\title{
'N VIDEOGEBASEERDE TUTOR ONDERRIG- EN ONDERSTEUNINGSPROGRAM VIR EERSTEJAAR VERPLEEGKUNDE STUDENTE
}

\author{
P.P. du Rand en E.M. Bitzer
}

\begin{abstract}
A video-based method of instruction was introduced to develop students academically as well as to implement parallel medium instruction. An action research approach was followed. Lectures were video-taped beforehand and worked through with the students by a tutor in scheduled Afrikaans or English periods. Simultaneously a live class situation was handled by the lecturer in the other language. Over and above these methods additional video-based suppor sessions were conducted by tutors for high risk students. A survey indicated that $85 \%$ of students were satisfied with this method of instruction. The perceptions of high risk students to VSI were positive and they passed the examinations. Video lectures need to be carefully planned in order to be acceptable as one of a number of possible instruction methods at a multi-cultural university.
\end{abstract}

\section{UTTTREKSEL}

' $n$ Videogebaseerde onderrigmetode is gevolg om studente akademies te ontwikkel sowel as om parallelmedium onderrig te implementeer. ' $n$ Aksienavorsingsbenadering is gevolg. Lesings word in Afrikaans en Engels vooraf op video opgeneem en gedurende geskeduleerde periodes deur 'n tutor in die Afrikaanse of Engelse klasgeleentheid met studente deurgewerk. Gelyklopend hanteer die dosent 'n "lewendige" klasgeleentheid. Bykomend tot geskeduleerde klasgeleenthede is videogebaseerde tutor ondersteuningsessies (VGTO) vir Afrikaanse en Engelse risikostudente ook deur tutors aangebied. Vyf en tagtig persent van die studente was tevrede met die onderrigmetode. Risikostudente het positiewe persepsies van die VGTO gehad en die vak geslaag. Videolesings moet egter goed beplan word. Dit blyk dat die videogebaseerde tutorbenadering een van verskeie onderrig - moontlikhede is wat benut kan word aan ' $n$ kultuurdiverse universiteit.

\section{INLEIDING}

Eerstejaar Verpleegkunde studente aan die Departement Verpleegkunde, UOVS was vir baie jare hoofsaaklik Afrikaanssprekend en het uit 'n homogene skoolstelsel gekom. Die situasie het egter sedert 1990, onder meer weens grootskaalse politieke veranderinge, gewysig en tans het alle voormalige blanke universiteite ' $n$ standhoudende toename in die toelating van swart studente. Voorgraadse swart studente het byvoorbeeld in $199420 \%$ van die departement se totale voorgraadse studentetal uitgemaak en $17 \%$ van nuweling eerstejaar studente.

Om hierdie studente akademies te ontwikkel. tot ware professionaliteit te vorm en parallelmedium onderrig te implementeer het talle nuwe uitdagings na vore gebring.

\section{PROBLEEMSTELLING EN LITERATUURSTUDIE}

Verpleegkunde opleiding aan universiteite is te duur om hoë druip-en slytasiesyfers van studente te bekostig. Identifisering en ondersteuning van studente wat vroeg in hul opleiding swak presteer, is dus van kardinale belang. Hoe hierdie ondersteuning presies behoort plaas te vind, is tans onseker (Burris, 1991:12). Dit bly ook problematies om algemene faktore te isoleer wat studenteprestasic op eerstejaarsvlak beinvloed (Tinto, in Martin \& Arendale, 1993:3).

Behalwe dat bogenoemde ook van toepassing op swart studente kan wees, is dit 'n feit dat die meerderheid swart studente ' $n$ onderwyskundige agterstand het weens gebrekkige skoolopleiding.
Eerstejaar verpleegkunde studente in die algemeen ervaar ook kultuurskok wanneer hulle tot die universiteit toetree. By die swart student wat meer aanpassings moet maak aangesien weinig voorbereiding vir die universiteit plaasgevind het, kan dit tot verhoogde stres aanleiding gee. Lajkowicz (1993:235) ondersteun hierdie waarneming:
"It is imponant that nurses become sen- sitive to the cultural differences of their co-workers and the effects that these dif- ferences can have on the work setting. Nurse educators play an important role in increasing this cultural awareness."

Die studente getalle van eerstejaars in verpleegkunde kan afhangende van die aantal goedgekeurde poste, tussen 80 en 120 varieer. Sewentien persent, naamlik 14 swart- en drie wit studente, het in 1992 Fundamentele Verpleegkunde gedruip.

Tydens herhaling van die vak is ondersteuning in die vorm van klein groeponderrig aan hierdie studente gegee, waama hulle geslaag het. Dit is egter " $n$ onmoontlike taak vir een dosent om in gewone klastye aan die behoeftes van al hierdie studente te voldoen. Parallelmedium onderrig (dit wil sê die aanbieding van afsonderlike klasgeleenthede in Afrikaans en Engels) het die werklas van die dosent verdubbel.

Baanbrekerswerk is onder leiding van Martin en Blanc aan die Missouri universiteit in Kansas City gedoen om hoë risikostudente (dit wil sê studente wat waarskynlik sou druip of hul studies staak) te ondersteun. Video-based Supplemental Instruction (VSI) en Supplemental Instruction (SI) is met groot sukses aangewend (The Center for Academic Development, 1993).

In 1993 het die navorsers 'n seminaar van genoemde persone bygewoon en die waarde van veral VSI as ' $n$ onderrigmetode besef. Hierdie besef het onder meer daartoe aanleiding gegee dat die Departement Verpleegkunde begin het om met ' $n$ gewysigde vorm van VSI te eksperimenteer.

\section{DOELSTELLINGS}

Die doel van die eksperiment was vierledig. naamlik: 


\section{TABEL 1: Aanbiedingskedule vir een week}

AFRIKAANSE KLAS 88 STUDENTE

Woensdag

Lewendige klas waargeneem deur dosent

Vrydag deur tutor

\section{ENGELSE KLAS - 15 STUDENTE} Lewendige klas waargeneem deur dosent
Video ondersteun deur tutor
- om studente die geleentheid te bied om by te woon;

- om akademiese ondersteuning aan studente te bied;

- om studente ' $n$ verskeidenheid leergeleenthede te bied; en

- om die onderriglading van dosente te hanteer.

\section{METODOLOGIE}

' $n$ Aksie navorsingsbenadering is gevolg. Hierdie benadering is veral geskik vir die oplossing van probleme en onmiddellike toepassing veral in onderrigsituasies (Bitzer, 1990:10; Sheehan, 1986:201). Die navorsers was in die rol van deelnemers en dus direk by die probleem betrokke. Die vier stadia van Kurt Lewin se aksie navorsingsbenadering is gevolg (Kemmis \& McTaggart, 1982;

\section{AKSIE NA VORSINBSBENADERING VAN LEWIN}

Volgens McCaugherty (1991:535) is die eerste navorsingstap om ' $n$ plan van aksie te ontwerp. In die studie wat uitgevoer is, is ' $n$ nuwe onderrigmetode vir die akademiese ontwikkeling en ondersteuning van studente geimplementeer. Die aksie is gemonitor deur middel van observasies, onderhoude en vraelyste aan studente. Sheehan (1986:201) maak melding dat die strategie van dataversameling dieselfde is as by ander navorsingsbenaderings. Die volgende stap behels implementering (act) van die ontwerp en om die aksie te observeer. $\mathrm{Na}$ aksie volg klasgeleenthede in of Afrikaans of Engels Zuber-Skerritt, 1991). reflektering (reflekterende denke/besinning) waarop veranderinge en aanpassings gemaak word. Die ontwikkelingsiklus word dan herhaal. Daar is nie ' $n$ beperking op die aantal kere waarop die siklus herhaal word nie.

\section{GELDIGHEID EN BETROUBAARHEID} die sigsgeldigheid van aksienavorsing waarborg dat die bevindinge van hierdie soort navorsing met die werklikheid ooreenstem. Betroubaarheid kan gekontroleer word deur interpretasies van navorsers en deelnemers te vergelyk.

Die vraelyste wat in die ondersoek benut is, het van ongeslote (oop) vrae gebruik gemaak en is aan onderwyskundiges voorgelê vir sigsgeldigheid. ' $n$ Betroubaarheidskoëffisiënt is ook nie statisties bepaal nie omrede konstantheid aanvaar is na die beoordeling van die kundiges.

\section{AKSIEPLAN}

Die aksieplan wat in die studie gevolg is, kan soos volg saamgevat word: Lesings word in Afrikaans en Engels vooraf op video opgeneem en gedurende geskeduleerde periodes deur ' $n$ tutor in die Afrikaanse of Engelse klasgeleentheid met studente deurgewerk. Gelyklopend hanteer die dosent "n "lewendige" klasgeleentheid (dit wil sê waar die dosent fisies teenwoordig is) in die alternatiewe medium. Tabel 1 verskaf in voorbeeld van ' $n$ tipiese lesingweek.

Behalwe geskeduleerde klastye word addisionele videogebaseerde tutor ondersteuningsessies (VGTO) vir Afrikaanse en
Greenwood (in Webb, 1989:405) oordeel dat

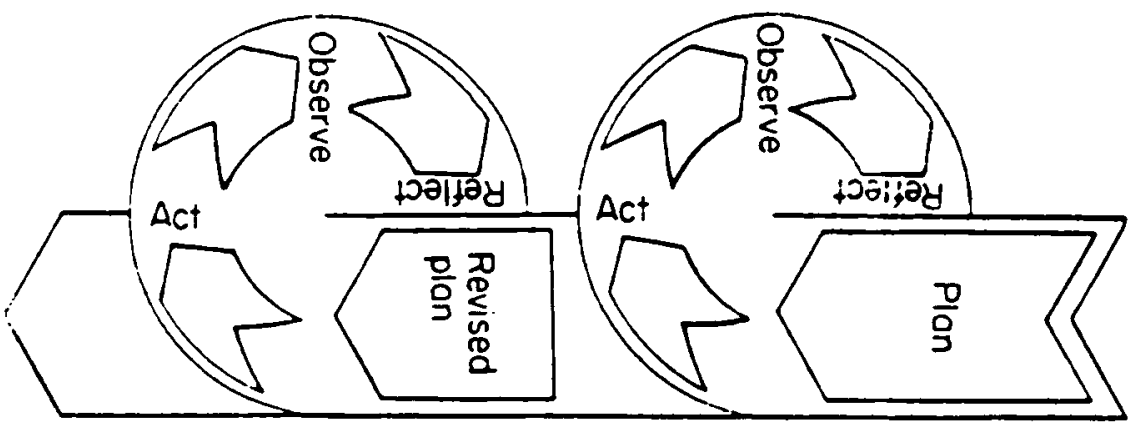

Engelse risikostudente geskeduleer. ' $n$ Risikostudent word gereken as 'n student met 'n hoë potensiaal om die kursus te staak of te druip. Die tutor, 'n geregistreerde verpleegkundige, benut gedurende die tutorklasse ' $n$ videoband, kan dit verskeie kere stop en besprekings aanmoedig. Hierdie tutorklasse vind in klein groepverband plaas volgens ' $n$ samewerkende leerbenadering waar studente in interaksie met mekaar werk in 'n veilige leeromgewing. Tydens besprekings word kritiese denke bevorder omrede die klem op toepassings en probleemoplossing gelê word

\section{IMPLEMENTERING VAN AKSIEPLAN}

\section{Videoproduksie}

Alle lesings van Fundamentele Verpleegkunde I is aan die begin van 1994 op videoband geplaas. Die lengte van videos varieer tussen 15 minute en 40 minute afhangende van die doelwitte en inhoud van lesings.

\section{Aanstelling, pligte en opleiding van} tutors

Vir die doeleindes van die eksperiment is twee tutors, 'n Afrikaans- en Engels- sprekende, aangestel. Albei is geregistreerde verpleegkundiges wat bereid was om op ' $n$ deeltydse basis insette te lewer. Twee van die aanwysers van potensieël suksesvolle tutors is geneem as (a) die wyse waarop tutors hul pligte verrig en (b) hul houding teenoor studente.

Die taak van die tutor is tweeledig, naamlik om gedurende sommige geskeduleerde periodes die klas met behulp van ' $n$ videoband te hanteer en VGTO sessies, wat addisioneel tot gewone klastye geskeduleer is, waarneem.

Gedurende die klastye is tutors verantwoordelik om studente se leerbehoeftes te monitor sodat die video onmiddellik gestop kan word wanneer die studente dit versoek of wanneer die tutor dit noodsaaklik ag. $\mathrm{Na}$ afloop van die video fasiliteer die tutor ook groepbesprekings. Die onderwerpe vir bespreking is deur die dosent uitgewerk.

Voor aanvang van die projek het tutors ' $n$ opleidingsessie van agt uur deurloop. Leerfasiliteringstegnieke is bespreek en ingeoefen. ' $n$ Belangrike aspek behels dat die tutors en dosent weekliks moes skakel oor onder meer die videolesing sowel as waarop klem in besprekings geplaas moet word. Probleme sowel as probleemstudente is bespreek, terwyl die bywoningsregister ook op datum gebring is. Leiding is ook aan tutors verskaf oor die addisionele videogebaseerde gesprekgeleenthede vir risikostudente.

a Videogebaseerde tutor onder. steuningsessies aan risikostudente

Hierdie sessies, is afhangende van die behoefte van studente, addisioneel een of twee keer per week deur die tutor aan beide Afrikaanse en Engelse risikostudente aangebied. Hierdie sessies is ook periodiek 
deur die dosent bygewoon sodat studente ook in klein groepverband met die dosent kon skakel. Observasies van individuele studente het veral tydens besprekings in hierdie sessies plaasgevind. Die tutor is nie veronderstel om te doseer gedurende hierdie klasse nie. Die video kan as ' $n$ hulpmiddel gebruik word en studente deel die tutor mee watter gedeeltes van die video hulle herhaal wil hê. Moeilike konsepte word bespreek en die tutor skep 'n klimaat waarbinne die student uit eie ervaring kan leer. Studente word aangemoedig word om te praat, te skryf, vorige ervarings in verband te bring, die leerstof toe te pas en dit deel van hulle eie ervaring te maak. Aandag word ook aan studiemetodes gegee.

Seleksie van studente vir videogebaseerde ondersteuningsessies

Bywoning van alle klasse is vrywillig. Studente word genader deur die dosent nadat die eerste toets se uitslae bekend is. Studente met 'n toetspunt onder $45 \%$ word na die sessies uitgenooi. Vir die afgelope twee jaar het die studente positief op hierdie uitnodigings gereageer en gereeld die klasse bygewoon. Veral wanneer hulle punte gewoonlik met die tweede toets verbeter, besef hulle deeglik die waarde van hierdie sessies.

\section{Inligting aan studente}

Gedurende die oriëntasietydperk is die projek in besonderhede aan die studente verduidelik ' $n$ Inligtingstuk is ook aan hulle verskaf, wat onder meer die volgende insluit: Datum, tyd, lokaal, onderwerp van lewendige lesing, dosent se besonderhede, onderwerp van videolesing, tutor se besonderhede, toetsdatums en onderwerpe waaroor hulle getoets gaan word.

\section{Klasbywoning}

Aangesien verpleegkunde studente in diens van die Provinsiale Administrasie is, is hulle verplig om alle geskeduleerde lesings by te woon. ' $n$ Bywoningsregister word dus bygehou. Alhoewel die tutorklasse vrywillig is, is daar onder die aandag van studente gebring dat indien hulle sou besluit om die klasse by te woon, hulle dit op 'n gereelde basis moes doen.

\section{OBSERVASIES EN REFLEKTERING}

D Toets- en eksamenresultate van studente Die cerste toets is geskryf vier weke nadat die program geimplementeer is en die tweede toets ongeveer sewe weke later. Tabel 2 toon ' $n$ normale verspreiding van die toetspunte wat goed vergelyk met die toetsresultate van studente van die vorige jaar. Studente (12\%) wat tussen $21 \%$ en $44 \%$ in hul cerste toets behaal het, is uitgenooi om die addisionele VGTO klasse by te woon. Hierdie studente het sewe VGTO klasse bygewoon voordat hulle die volgende toets geskryf het. In die tweede toets, sowel as in die eksamen het al die studente wat tutorklasse bygewoon het, geslaag. Ná die tweede toets is studente weer geselekteer vir bywoning van tutorklasse. Die

TABEL 2:

Toets en eksamenresultate - eerste semester 1994

\begin{tabular}{|cccc|} 
KLASINTERVAL & Eerste toets & Tweede toets & Eksamenpunt \\
$75-92$ & $F(\%)(N=95)$ & $F(\%)(N=94)$ & $F(\%)(N=95)$ \\
$74-60$ & $8(8,4 \%)$ & $29(30,8 \%)$ & $8(8,42 \%)$ \\
$59-50$ & $29(30,5 \%)$ & $38(40,4 \%)$ & $45(47,3 \%)$ \\
$49-45$ & $29(30,5 \%)$ & $14(14,8 \%)$ & $39(41,05 \%)$ \\
$21-44$ & $17(17,9 \%)$ & $5(5,3 \%)$ & $1(1,05 \%)$ \\
& $12(12,6 \%)$ & $8(8,5 \%)$ & $2(2,10 \%)$ \\
\hline
\end{tabular}

\begin{tabular}{|cccc|}
\hline TABEL 3: & \multicolumn{2}{c|}{ Toetsresultate van Engelssprekende studente } \\
KLASINTERVAL & Eerste toets & Tweede toets & Eksamenpunt \\
& $F(\%)(N=12)$ & $F(\%)(N=12)$ & $F(\%)(N=11)$ \\
$75-80$ & $2(16,6 \%)$ & $4(33,3 \%)$ & - \\
$74-60$ & $3(25 \%)$ & $6(50 \%)$ & $7(63,6 \%)$ \\
$59-50$ & $7(58 \%)$ & $1(8,3 \%)$ & $4(36,3 \%)$ \\
$49-45$ & - & - & - \\
$21-44$ & - & $1(8,3 \%)$ & - \\
\hline
\end{tabular}

twee studente wat in die eksamen gedruip het, is uitgenooi om tutorklasse by te woon, maar het nie opgedaag nie.

Tabel 3 toon dat al die Engelse studente wat addisionele tutorklasse vanaf die begin ontvang het, die eerste toets geslaag het. " $n$ Moontlike verklaring kan wees dat hulle akademiese ondersteuning effektief was, hoewel die grootte van die groep ook 'n beduidende rol kon gespeel het. Met betrekking tot die tweede toets is hoër punte in geheel verkry, alhoewel een student gedruip het as gevolg van huislike omstandighede. Die eksamenpunt dui daarop dat $7(63,6 \%)$ meer as $60 \%$ behaal het en $4(36,3 \%)$ meer as $50 \%$. Een student het gestaak omrede sy gevoel het dat verpleegkunde die verkeerde beroepskeuse was. Wanneer in ag geneem word dat hierdie studente almal risikostudente was, is die $100 \%$ slaagsyfer bemoedigend.

\section{Die ervarings van studente}

Vraelyste is in beide die finale klas- en VGTO periode aan studente gegee om te voltooi. Alhoewel daar spesifieke vrae was, was daar geleentheid om hul eie menings te lug. Motiverings vir elke JANEE vraag is ook gevra. Tabel 4 toon die frekwensie van studenteresponse.

\section{TABEL 4: $\quad$ Studentemenings oor videolesings}

GERIGTE VRAE OM MENINGS TE BEPAAL

Respons van studente $(\mathrm{N}=90)$

irriterend kort-kort afgeskakel word, terwyl $5(5,5 \%)$ voorgestel het dat die videos kort en kragtig moet wees en $7(7,7 \%)$ gevoel het dat hulle die persoonlike kontak van 'n dosent mis.

Ten opsigte van vrae 2 en 3 (tabel 4) is die volgende opmerkings in tabelvorm (kyk tabelle 5 en 6) vervat. Opmerkings gemaak ten opsigte van video-opnames (tabel 7) was soos volg:

- Transparante was onduidelik (13\%)

- Klankbaan was swak (11\%).

- Die videos was te lank $(5,5 \%)$

- Lesing kom direk uit handboek $(4,4 \%)$. 
Negatiewe opmerkings oor die aard en kwaliteit van videolesings, sowel as die relatief hoë frekwensie van studente wat aangedui het dat videobande "onduidelik" en vervelig was, het nie die prestasie van die studente beïnvloed nie.

Onder algemene opmerkings het twee studente die dosent en tutor gelukgewens met die moeite wat vir studente gedoen is. Dertig $(33,3 \%)$ studente het gevra dat klasse nie op 'n Vrydagmiddag aangebied moet word nie en daar is deur $10(11 \%)$ gevoel dat beide die klasse en die videos korter moet wees.

Terugvoering vanaf studente oor addisionele videogebaseerde tutor ondersteuningsessies (VGTO)

Tien Afrikaanse studente en 11 Engelse studente (10 swart) het bogenoemde sessies bygewoon. Al 10 Afrikaanse studente het aangedui dat hulle by die sessies baat gevind het. Van die 11 Engelse studente het 10 aangedui dat hulle baat gevind het.

Die redes wat deur Afrikaanse studente verskaf is, was die volgende (frekwensies in hakies):

- Wanneer werk bespreek is, het dit duideliker geword (4).

- Kon werk met mekaar deel (4).

- Daar was meer geleentheid om vrae te vra (3).

- Het meer aandag gekry (2).

- Punte het verbeter (2).

- Het positief oor werk geraak (2).

Die Engelse studente se motiverings was soos volg:

- Besprekings wat tydens die sessie gevoer is, was goed (6).

- Het gehou van die aandag wat hulle tydens die sessie ontvang het (4).

- Wanneer iets nie verstaan is nie, kon die video teruggespeel word (3).

- Van al die leergeleenthede is die meeste by dié sessie gebaat (2).
TABEL 5: Opmerkings oor tutor (Vraag 2)

POSITIEWE OPMERKINGS

Aantal response

Het video gestop en vrae gevra

$F(\%)(N=90)$

Vraag wat tutor vra, was goed

$14(15,5 \%)$

Was getrou en altyd teenwoordig

$13(14,4 \%)$

Tutor kon vrae beantwoord

$11(12,1 \%)$

Besprekings het student op hoogte gehou

$6(6,6 \%)$

Was voorbereid

$6(6,6 \%)$

$4(4,4 \%)$

Het by tutor geleer

$4(4,4 \%)$

Tutor het videos bespreek

$3(3,3 \%)$

\section{NEGATIEWE OPMERKINGS}

Aantal response

$F(\%)$

Het slaperig geraak

$6(6,6 \%)$

$4(4,4 \%)$

$4(4,4 \%)$

$3(3,3 \%)$

Wil meer visuele videos sien (sketse, prente)

aanbied van lewendige kontakgeleenthede (Vraag 3)

TABEL 6: Opmerkings oor dosent tydens

\section{POSTIEWE OPMERKINGS}

Interessante voorbeelde is vermeld

Dosent het moeite gedoen

Onduidelikhede is bespreek

Interaksie het plaasgevind

Was ' $n$ rolmodel

NEGATIEWE OPMERKINGS

Het gou verveeld geraak

Klasse was langdradig

Aantal response
$F(\%)(N=90)$
$15(16,6 \%)$
$11(12,2 \%)$
$9(10 \%)$
$5(5,5 \%)$
$5(5,5 \%)$

Aantal response $F(\%)$

$2(2,2 \%)$

$2(2,2 \%)$

TABEL 7: Evaluering van videos (student kon meer as een respons verskaf)

EVALUERING VAN VIDEO

Goed

Onduidelik

Vervelig
Negatiewe aspekte wat uitgelig was by vyf Afrikaanse studente was dat die tyd wanneer die sessies aangebied is vir hulle ongeleë was. Twee het melding gemaak dat die tydsduur

\begin{tabular}{|c|c|c|c|c|}
\hline \multicolumn{5}{|c|}{ TABEL 8: Studente persepsie van tutor } \\
\hline \multirow[t]{2}{*}{ PERSEPSIE } & \multicolumn{4}{|c|}{ Respons } \\
\hline & \multicolumn{2}{|c|}{ Engelse studente } & \multicolumn{2}{|c|}{ Afrikaanse studente } \\
\hline Tutor & Ja & Nee & Ja & Nee \\
\hline het studente se name geken & 10 & - & 10 & * \\
\hline het oogkontak gemaak & 10 & - & 10 & - \\
\hline het as rolmodel opgetree & 8 & 2 & 10 & - \\
\hline het genoeg tyd vir vrae toegelaat & 10 & - & 8 & 2 \\
\hline het ' $n$ sin vir humor & 10 & $\cdot$ & 9 & 1 \\
\hline isaanpasbaar & 10 & - & 10 & - \\
\hline help my met studiemetodes & 8 & 2 & 4 & 6 \\
\hline
\end{tabular}

van die tutorsessie te kort was. Van die Engelse studente het vyf gemeld dat die sessies te kort was vir besprekings.

Uit tabel 8 blyk dit dat die studente ' $n$ positiewe persepsie van die VGTO-sessies gehad het. Die Engelse tutor het in vergelyking met die Afrikaanse tutor meer aandag aan studiemetodes gegee - moontlik omdat daar dalk 'n groter behoefte was.

Al die studente het aangedui dat hulle wil voortgaan met die onderrigsisteem soos dit in die eerste semester hanteer is. Alhoewel sommige studente hoè punte behaal het, het hulle verkies om die tweede semester met VGTO-sessies vol te hou. 


\section{BEVINDINGE VAN TWEEDE SEMESTER (1994)}

Daar is besluit om nie die tutors plaasvervangend in geskeduleerde klastye aan te wend nie, omdat risikostudente swak gevaar het in die praktiese eksamens en die tutors dus ook aangewend moes word om hulle in die praktyk te ondersteun. Daar is voortgegaan met die addisionele tutorklasse (sonder videolesings) as ondersteuning vir die teorie is. Aangesien die dosent nou al die lesings alleen moes waarneem moes die studente sekere afdelings as selfaktiwiteit behartig.

Aan die einde van die semester is daar weer vraelyste aan studente vir voltooiing oorhandig. Onder andere moes studente aandui of hulle die metode van die eerste semester (waar die tutor plaasvervangend in geskeduleerde klastye benut word) of tweede semester (waar alle lesings deur die dosent aangebied word) verkies. Vyf-en-vyftig (71\%) het gewone lesings verkies terwyl 22 (29\%) voorkeur aan die videometode gegee het. Wat opvallend was, is dat al die swart studente die videometode verkies het. ' $n$ Verblydende tendens was dat $75(91 \%)$ die selfaktiwiteit positief ervaar het.

Die getal studente in die Afrikaanse tutor ondersteuningsessies het gevarieer tussen 9-13 wat gereeld die klasse bygewoon het. Vyf van die studente het ook in die eerste semester die sessies bygewoon. Al die Afrikaanse studente het aangedui dat die tutorsessies hulle gehelp het om die werk te bemeester. Tien Engelse studente (swart) het die Engeise tutor ondersteuning bygewoon en nege het die sessies positief geëvalueer.

Die mees algemene opmerking wat deur studente gemaak is t.o.v. tutorsessies was dat dit vir hulle bevredigend was om in ' $n$ groep te leer.

\section{Toets- en eksamenresultate}

Volgens tabel 9 blyk dit dat studente buitengewoon goed in die cerste toets gevaar het. 'n Moontlike rede kan wees dat hulle oor in klein volume werk geëvalueer is.

In die tweede toets, wat 'n groot volume werk gedek het, het studente oor die algemeen swakker gevaar. Na elke toets is risikostudente telkens deur die dosent genader om tutorklasse by te woon. Al die studente het in die eksamen geslaag en een student het na die eerste toets gestaak.

\section{BESPREKING}

Die videogebaseerde tutorbenadering verg aanvanklik meer beplanning en insette van die dosent, maar bespaar op die lang duur dosent-student kontaktyd. Tutors kan in belangrike rol speel by veral risikostudente wat aanpassings en leerprobleme het, terwyl voortdurende belangstelling van die dosent noodsaaklik blyk te wees. Alhoewel studente aan die einde van die tweede semester van die studic die tradisionele lesingmetode verkies

TABEL 9:

Toets en eksamenresultate - tweede semester 1994

\section{KLASINTERVAL}

$>80$

$75-80$

$74-60$

$59-50$

49-45

$21-44$
Eerste toets

$F(\%)(N=93)$

$13(13,9 \%)$

$19(20,4 \%)$

$44(47,3 \%)$

$12(12,9 \%)$

$3(3,2 \%)$

$2(2,1 \%)$
Tweede toet

$F(\%)(N=93)$

$7(7,5 \%)$

$2(2,1 \%)$

$29(31,1 \%)$

$34(36,5 \%)$

$9(9,6 \%)$

$12(12,9 \%)$
Eksamenpunt

$F(\%)(N=92)$

$4(4,3 \%)$

$3(3,2 \%)$

$57(61,9 \%)$

$28(30,4 \%)$ het, was hulle in die eerste semester tevrede. Daar was nie groot verskille met betrekking tot resultate in die eerste en tweede semester nie.

Hoewel veralgemenings nie gemaak kan word nie, blyk dit dat veral die uitslag van die eerste toets ' $n$ goeie voorspeler van studente-risiko is.

Videolesings kan meer interessant gemaak word deur visuele materiaal te benut, byvoorbeeld ' $n$ foto van 'n drukseer wanneer van 'n drukseer melding gemaak word. Transparante kan ook in gefotostateerde formaat as aanvullingsmateriaal beskikbaar gestel word

Die volgende voorlopige aanbevellngs kan waarskynlik uit die studie gemaak word:

1. Risikostudente behoort vroegtydig geidentifiseer te word en aangemoedig word om ondersteuningsessies by te woon. Lesings op video moet vooraf goed beplan en gestnuktureer word. Dit is nie goed genoeg dat ' $n$ lesing in die ateljee opgeneem word sonder deeglike voorbereiding nie. Die "talking head" effek moet aandag kry deur videos aanskoulik te maak, vrae en gevallestudies in te bou en moet liefs nie langer as 20 tot 30 minute duur nie.

2. Studente moet vooraf goed vertroud gemaak word met die doel en prosedures van 'n videogebaseerde tutorprogram. Dit is wenslik dat videos as plaasvervangend nie te vroeg in die cerste studiejaar begin nie. Studente moet eers aan die dosent, nuwe kursus en universiteitsomgewing gewoond raak.

3. Die beskikbaarheid van veral kleiner besprekingslokale met videotoerusting is noodsaaklik vir die suksesvolle implementering van die program.

4. Tutors in verpleegkunde behoort gekwalifiseerde verpleegkundiges te wees aangesien professionalisering van die student ' $n$ belangrike rol speel. Daar kan gebruik gemaak word van verpleegkundiges wat nie voltyds werk nie. Voortdurende intense belangstelling van die dosent is uiters noodsaaklik. Tyd moet weekliks geskeduleer word vir vakkundige samesprekings tussen dosent en tutors. Motivering en aanmoediging vanaf die dosent is van besondere belang.

5. Aangesien risiko studente melding gemaak het van 'n vol eerstejaarprogram en soms duidelik uitgeput was, blyk dit

- dat hulle aangemoedig moet word om vir minder vakke te registreer sodat daar genoeg tyd is vir akademiese ondersteuning.

6. Talle nie-tradisionele (hoofsaaklik swart) studente is eerste geslag universiteitsgangers. Hulle vind die universiteitsomgewing vreemd en ervaar veral in die begin van die eerstejaar aanpassings. probleme wat studente uit 'n meer gesofistikeerde agtergrond nie beleef nie. Hulle is ook soms onbewus van die administratiewe verpligtinge. Voor hulle tot die universiteit toetree, behoort hulle volledig georiënteer te word tot hulle verantwoordelikhede en verpligtinge teenoor die universiteit en die eise wat daar aan hulle gestel sal word.

7. Dit blyk dat die videogebaseerde tutorbenadering een van verskeie onderrigmoontlikhede is wat benut kan word aan ' $n$ kultuurdiverse universiteit. ' $n$ Benadering wat oorweeg kan word, is om 'n kursus in drie dele (A-C) te deel, In deel $A$ is die dosent in sowel die Engelse as Afrikaanse klasgeleentheid teenwoordig. Hier word die kem van die kursus hanteer. In deel B word van multi-media pakette en tutors gebruik gemaak. Die fokus in deel B val op dié deel van die kursus wat perifeer van aard is. In deel $\mathbf{C}$ is daar ' $n$ komponent gestruktureerde selfstudie. Die relatiewe gewig van die onderskeie dele kan varieër namate die studie jare vorder.

\section{SAMEVATTING}

Die ontwikkeling van ' $n$ goeie tutorprogram is waarskynlik die beste opsie vir die nuwe parallelmedium onderrigsituasie wat op die Deparement Verpleegkunde wag. Daar kan dus voortgebou word op die werk wat gedoen is. Die opleiding van die tutors hoef nie slegs op videobenutting betrekking te hê nie, maar kan op leerfasiliteringsvaardighede en die akademiese ontwikkeling van studente fokus. Hierbenewens moet voortdurend met 
goedkoper onderrigmetodes geëksperimenteer te word wat nogtans effektief binne die konteks van " $n$ vak sal wees.

\section{VERWYSINGS}

BITZER, E.M. 1990. Enkele invalshoeke vir opvoedkundige navorsing, toegespits op navorsing oor universiteitsonderwys. Buro vir Universiteitsonderwys, UOVS.

BURRIS, B.M. 1991. Academic enrichment project for disadvantaged students. Chicago: State University.

KEMMIS, S. \& McTAGGART, R. 1982. The action research planner. Deakin University Press Victoria.

LAJKOWICZ, C. 1993. Teaching cultural diversity for the workplace. Journal of Nursing Education, 32(5):235-236.
MARTIN, D.C. \& ARENDALE, D.R. 1993. Supplement instruction: Improving first-year student success in high-risk courses. Columbia: University of South Carolina.

McCAUGHERTY, D. 1990. The use of a teaching model to promote reflection and the experiental integration of theory and practice in first-year student nurses: An action research study. Journal of Advanced Nursing, 16:534-543.

SHEEHAN, J. 1986. Aspects of research methodology. Nursing Education Today, 6(1):193-203.

THE CENTER FOR ACADEMIC DEVELOPMENT. 1993. VSI training manual: Video-based supplemental instruction. Kansas: University of Missouri-Kansas City.
WEBB, C. 1989. Action research: Philosophy, methods and personal experiences. Journal of Advanced Nursing, 14(5):403-410.

ZUBER-SKERRIT, O. 1991. Action research in higher education. Brisbane: Centre for the Advancement of Learning and Teaching.

Paula P. du Rand

M.Soc.Sc. (Verpleegkunde), UOVS Lektrise, Departement Verpleegkunde Universiteit van die Oranje-Vrystaat

Eli M. Bitzer

D.Ed., UOVS

Professor Buro vir Ademiese Ontwikkeling

Universiteit van die Oranje-Vrystaat 